\title{
Theoretical and Experimental Investigation of Hydromechanical Extrusion Process
}

\author{
Olesya Yurevna Agapitova, Sergey Vasilievich Byvaltsev*, Alexander Georgievich Zalazinski \\ Institute of Engineering Science, Ural Branch of the Russian Academy of Sciences, Yekaterinburg, Russia

\section{Email address:} \\ agapitova.olesya@yandex.ru (O. Y. Agapitova), s_ikar@mail.ru (S. V. Byvaltsev), zalazinskiy.alexander@yandex.ru (A. G. Zalazinskiy) \\ *Corresponding author
}

\section{To cite this article:}

Olesya Yurevna Agapitova, Sergey Vasilievich Byvaltsev, Alexander Georgievich Zalazinski. Theoretical and Experimental Investigation of Hydromechanical Extrusion Process. American Journal of Mechanical and Industrial Engineering. Vol. 2, No. 1, 2017, pp. 17-23.

doi: 10.11648/j.ajmie.20170201.13

Received: October 26, 2016; Accepted: November 17, 2016; Published: December 29, 2016

\begin{abstract}
The theoretical and experimental investigation of the process of hydromechanical extrusion (HE) of aluminum alloys Al 5056 was carried out. The aim is to determine the optimal parameters of this process. These parameters were determined to minimize the extrusion force and damage factor of a workpiece by using explicit finite elements method. The results were presented in a visual form and were shown that use of active friction forces reduces the extrusion force. Statistical processing of the experimental data gave regression equations for definition the damage factor and the value of the specific extrusion stress.
\end{abstract}

Keywords: Hydromechanical Extrusion, Computer Simulation, Extrusion Force, Damage Factor

\section{Introduction}

Currently, substantial difficulties appear at some industrial enterprises when high-precision extracting sections made of precious and hard-to-deform nonferrous metals and alloys and of fibrous composite materials are processed by pressure (extrusion and drawing). These exacting sections should have high surface smoothness and the given accuracy of sizes over the section, maintain their chemical composition in the limits of their technical specifications at processing, and take the required physicochemical properties [1]. The various methods of solving these problems are known.

For example, the extracting sections made of nonferrous metals in nonferrous metallurgy are obtained by hot extrusion of round castings with the follow-up operations of rolling and drawing. It is reasonable to apply these technologies when producing the huge volumes of goods; however, in the case of small-volume production the expenditures are found to be unreasonably high and the process is economically inefficient.

The basic disadvantages of the available manufacturing technologies of workpiece extrusion are as follows: high power inputs for heating the metal; necessity of using several types of complex equipment; high cyclicality of production which is related to setting up several types of equipment; possibility of contamination of precision alloys at processing; and occurrence of a butt-end with weight reached thirty percent of workpiece weight. These disadvantages are result in necessity of workpiece section length increasing. However, with increasing of workpiece length the pressure load on the tool rises significantly.

The methods of backward extrusion, hydroextrusion and extrusion with active influence of friction forces allow decreasing the pressure load on the tool at comparable drawforming and initial workpiece length [2].

Recently the interest in hydrostatic extrusion as a method for processing hard-to-deform materials has been increasing considerably as it was shown that hydrostatically extruded workpiece materials exhibit significantly enhanced strength and plastic characteristics [3-6]. Application of high pressure prevents formation of cracks and enables very high degrees of plastic deformation to be achieved at a high rate of deformation [7].

The hydroextrusion process allows receiving highaccuracy sections without workpiece heating and with minimal surface friction. However, the use of this pattern causes significant technical difficulties at attempts to achieve the semi-continuous deformation process by the "workpieceby-workpiece" scheme. In addition, because of the 
significant change in liquid volume under high pressure during deforming the acceleration of the workpiece motion and even its "shot" at the process end are possible. To prevent these negative phenomena a number of measures substantially complicating the hydroextrusion technology are used. In particular, the hydromechanical extrusion methods combining the high hydrostatic pressure with the mechanical force are known [8-10]. Their use provides the complete control of the workpiece and product motion during deforming, and, consequently, one can achieve semicontinuous production process by the "workpiece-byworkpiece" scheme. The series of hydromechanical extrusion schemes is described in $[11,12]$.

\section{Description of the Hydromechanical Extrusion Concept}

When carrying out hydromechanical extrusion the workpiece is placed into the container and deformed at the given length, the liquid pressure is released. After that, the next workpiece is placed in and is deformed at the given length, etc. [11, 12]. The process is conducted with the application of pressure to the back faces of the workpieces that is of $10-15 \%$ of the total deformation force [13]. The technological feature of the process is the envelopment of the entire workpiece by the actuating medium and the substitution of dry friction of the extruded metal on the container wall and the matrix channel by the liquid friction with the corresponding reduction of the extrusion pressure, which is often very high.

There are also a number of methods of workpiece extrusion with application of active influence of friction forces at which the deformation non-uniformity and necessary extrusion force are reduced. After the conducted analysis of the contemporary energy efficient methods of workpiece extrusion realization we came to the conclusion that the HE method completely meets requirements which were described at the beginning of the article [14]. Taking into consideration the difficulties of realization of HE process there is a necessity in developing the modern system of HE process control [10, 15 and 16]. The mathematical apparatus for modeling the extrusion process is the base of development of the control computer-aided system. The mathematical modeling is considered by the authors of the article as the base for subsequent development of computeraided systems: technological production preparation, design of equipment and a tool, control of a technological process, control of machines and aggregates, and production quality control $[17,18]$.

\section{Scheme of Development and Research of HE Process}

Fig. 1 shows the development and research scheme of HE process using software. According to this scheme the design of a new technological process is not limited to the creation of mathematical and computer models of the process. It is also need to develop a technology for manufacturing of parts, to carry out the engineering analysis and monitoring of workpieces damage, to develop the appropriate technological equipment subject to the limits of the applied equipment, to plan the experimental study. To accomplish the tasks the integration of various software tools of CAD and CAE systems (SolidWorks and DEFORM 2D (3D) software packages) with the system of computer mathematics MATLAB was carried out. The software package SimulaTMP proposed in [19] is taken as a basis for the design system. SimulaTMP is assigned for modeling the processes of metal working by pressure. As a result of the conducted research works the mathematical model of HE has been added into the knowledge base of the software system.

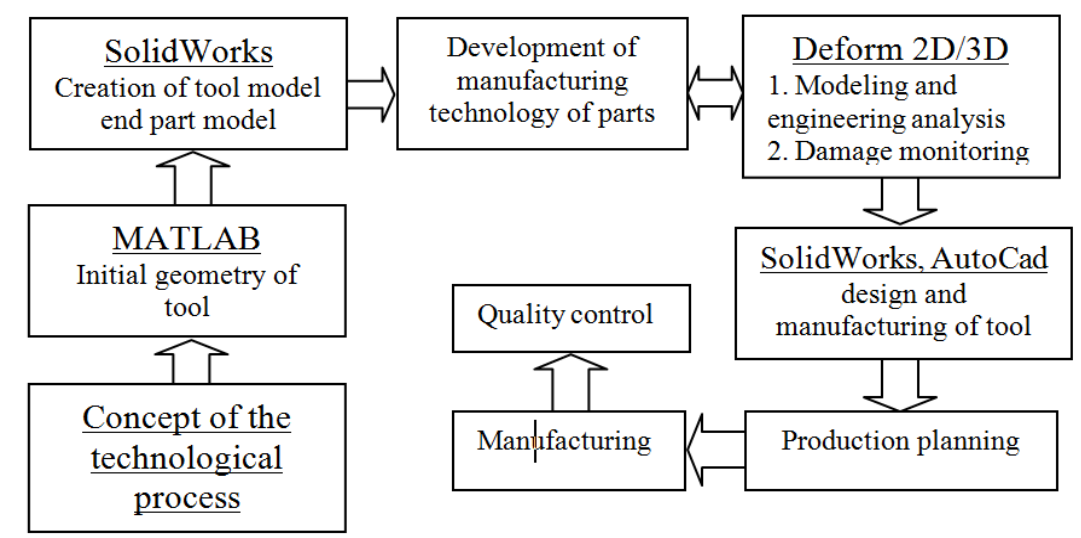

Figure 1. Pattern of development and research of the HE process with application of software tools.

\section{Computer Simulation of the HE Process}

In the study we considered the HE process by varying the draw from 2 to 8 and the coefficient of friction from 0.1 to 0.4 for a given diameter of a workpiece $9 \mathrm{~mm}$.

At the initial stage of the study the researchers entered the raw data, and then the preliminary calculation of the tool geometry and the calculation of the basic parameters of the 
technological process were made within the constraints on the capability of the equipment, on the specific pressures on the tool, on the heterogeneity of workpiece deformation.

Both at the hydromechanical extrusion and at the direct extrusion there is an optimum angle of die conicity. This angle minimizes the required extrusion pressure. The optimum angle is determined according to [20]. With development of computer engineering and increasing its productivity it became possible to compute the optimal die angle. After entering the raw data the minimization of extrusion force is made taking into account the given initial conditions. Then the initial geometry parameters (die angle) are defined depending on the value of the friction ratio and the drawing value. The results are displayed in a table in a separate window [16].

\section{The Results of Computer Simulation}
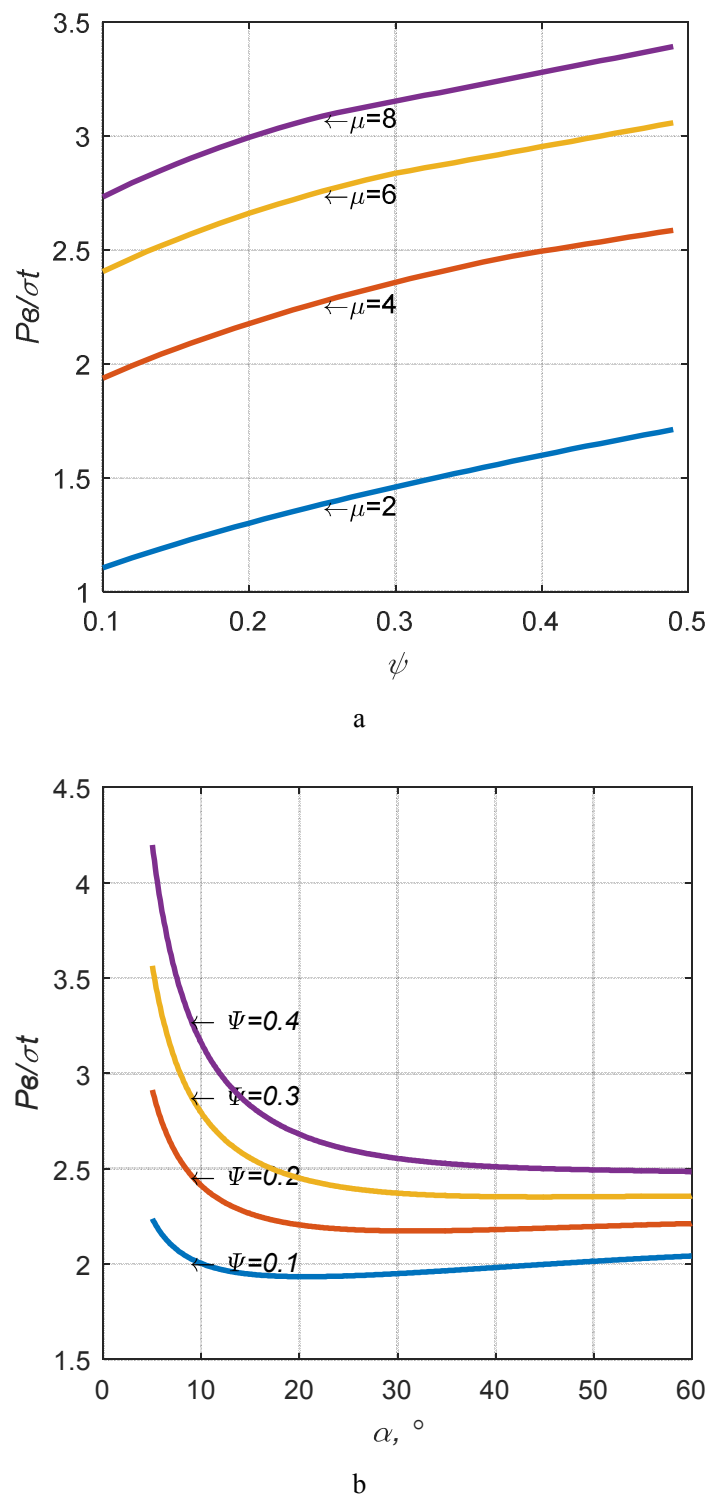

Figure 2. Extrusion force as a function of the friction value at different draws (a); extrusion force as a function of the die angle at different friction ratios (b).
Below the results of a computer simulation of the HE process are shown. The extrusion pressure depends not only on the die angles but also on the value of the friction ratio. Fig. 2a shows that with increase of the friction ratio the extrusion pressure also increases. In the case of optimum design of the die the extrusion force as a function of the drawing value at the constant initial diameter of a workpiece is shown in Fig. 2 b.

After the initial tool geometry is determined in accordance with the scheme shown in Fig. 3, a three-dimensional parametric model of production tooling and a workpiece is created and transmitted in the format *.XLS in the CAD package of Solid Works. The researcher has a possibility to modify the model (Fig. 3).

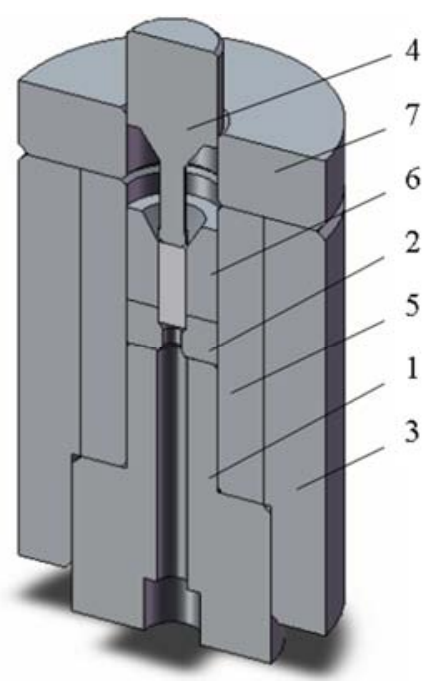

Figure 3. Three-dimensional model of tooling for hydromechanical extrusion.

1 - mouthpiece; 2 - deforming die; 3 - ram case; 4 - punch; 5 - container; 6 sleeve; 7 - bottom spacing ring.

On the base of the raw data as a result of determining the extrusion force and the optimum die angle the calculation of the tool sizes is carried out to provide the necessary rigidity of the construction.

After the tool model is edited through data export and import the parametric model (configuration details data) is transferred in the format *.igs (*.stl) to Deform2D (3D) of CAE package to simulation of the HE process. Then the engineering analysis of the data obtained by computer simulation is carried out.

In the package Deform2D (3D) the necessary calculations using the finite elements method were made (Fig. 4). The result of computer simulation of the HE process in the package DEFORM 2D is prediction of the filling of the deformation zone and the emergence of the defects, determining of necessary deformation force, deformation energy, stress-strain state, the flow velocity of the workpiece material and the lubricant layer. The deforming force was determined depending on the size of the workpiece, its shape, and friction ratio and material properties. Furthermore, by computer modeling the workpiece parameters such as the 
cumulative strain, the stress, the direction of the workpiece fiber, the possibility of destruction of the workpiece and tool wear were determined.

Fig. 4a shows a 3D model of the hydromechanical extrusion. Between the workpiece and the tooling there is a layer of lubricant. It is evident that during the deformation process the lubricating layer advances the workpiece that is possible due to active action of friction forces. Fig. $4 \mathrm{~b}$ shows the distribution of deformation intensities over the longitudinal section of the workpiece. It was found that the maximum intensity of deformation (indicated by the arrow in the figure) equal to 0.168 is observed in the center of deformation on the axis of symmetry of the workpiece.

Figure $4 \mathrm{c}$ shows the distribution of the average normal stresses over the longitudinal section of the workpiece. It is
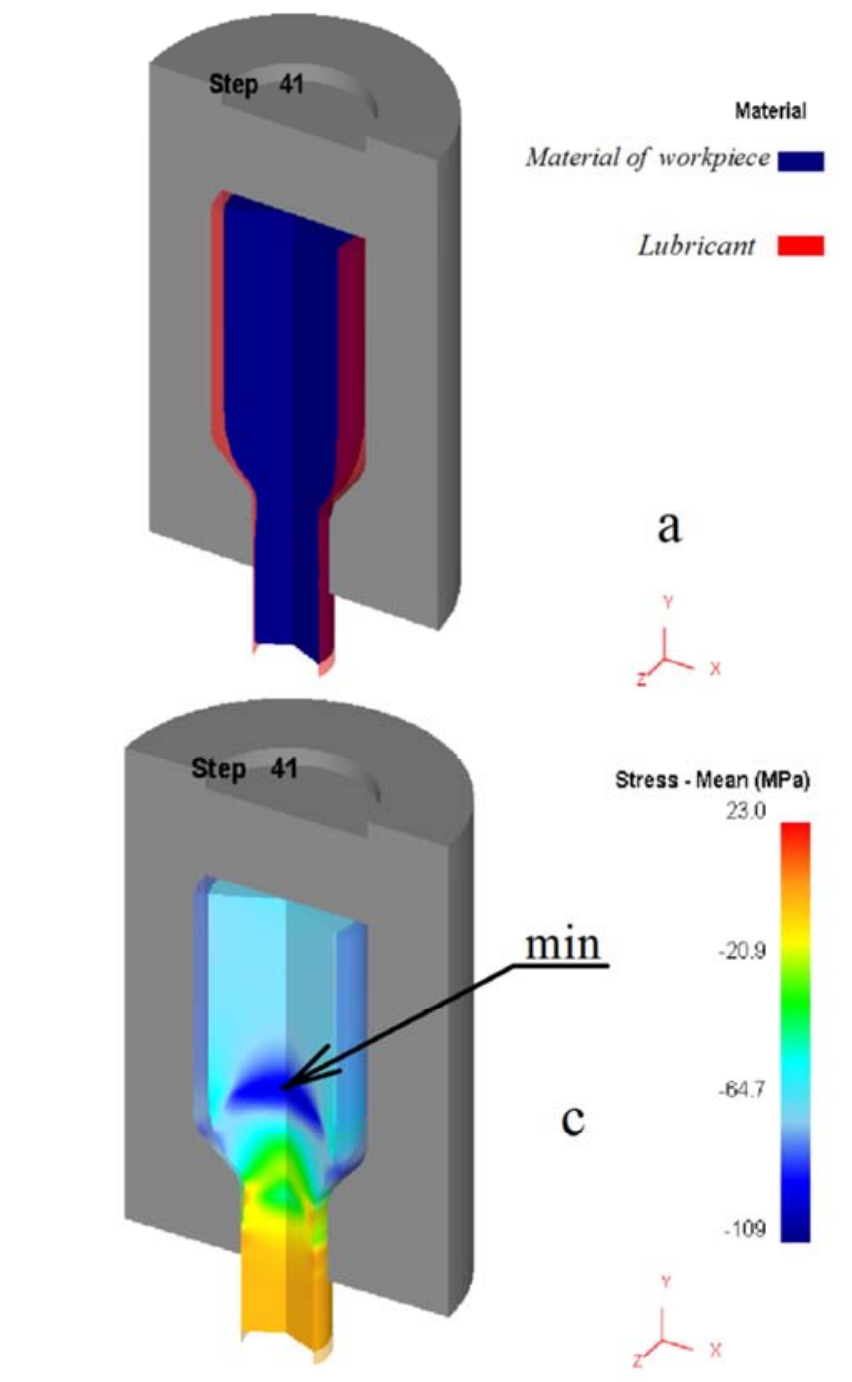

obvious that in the center of deformation the compressive stresses dominate. The minimum of the average normal stress (indicated by the arrow in the figure) equal to $-95,4 \mathrm{MPa}$ is observed on the axis of symmetry of the workpiece in the area disposed in the working cone of the die. Figure $4 \mathrm{~d}$ shows the distribution of stress intensity over the longitudinal section of the workpiece.

In the package DEFORM the computational simulation of the studied process, defining the stresses and the deformations of the junction points of the finite element grid, determination of the extrusion force at each iteration step were made. On the second stage the tool stress analysis is carried out (Fig. 5). The researcher also has a possibility to interact with the package DEFORM for run-time correction of the computation progress.

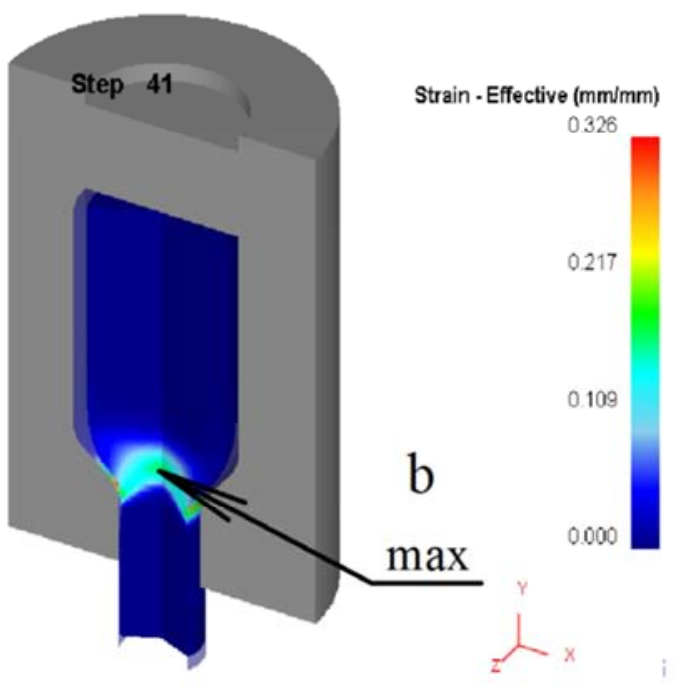

a - model of hydromechanical extrusion; b - distribution of effective strain; c - distribution of mean stresses; $d$ - distribution of effective stresses.

Figure 4. The results of computer simulation in the package Deform2D.

Figure 5 shows the distribution of equivalent stresses over the longitudinal section of the tool and the workpiece, the maximum equal to $330 \mathrm{MPa}$ is revealed in zone I. The engineering analysis of the HE process allows defining the optimum conditions of deformation by minimizing the extrusion force and the deformation inhomogeneity. Prediction of material workpiece damage allows to reveal the possible defects on the design stage and to generate the conditions for their prevention. The tool strength calculation provides a possibility of selection the material for tool production. 


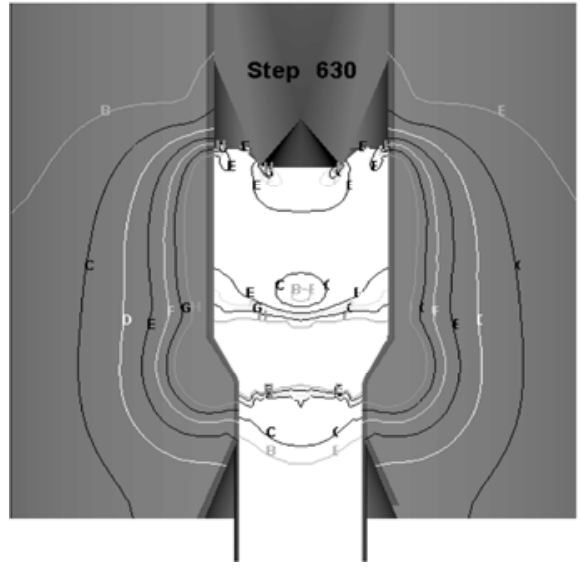

Stress - Effective (MPa)

$$
\begin{aligned}
A= & 0.000 \\
B= & 413 \\
C= & 82.5 \\
E= & 165 \\
E= & 205 \\
G= & 248 \\
H= & 289 \\
I= & 330
\end{aligned}
$$

Figure 5. The results of tool analysis in the package Deform $2 D(3 D)$

According to the results of computer simulation the drawings for tool production are developed.

\section{Experimental Investigation}

Cylindrical workpieces of aluminum alloy A15056 with diameter of $9 \mathrm{~mm}$ and length of $22 \mathrm{~mm}$ were extruded in all experiments. The definition of optimum technological parameters of the HE process on the condition of minimum damage and minimum extrusion force was the aim of the experimental investigation. Below the scheme and the results of the experimental investigation of the HE process are

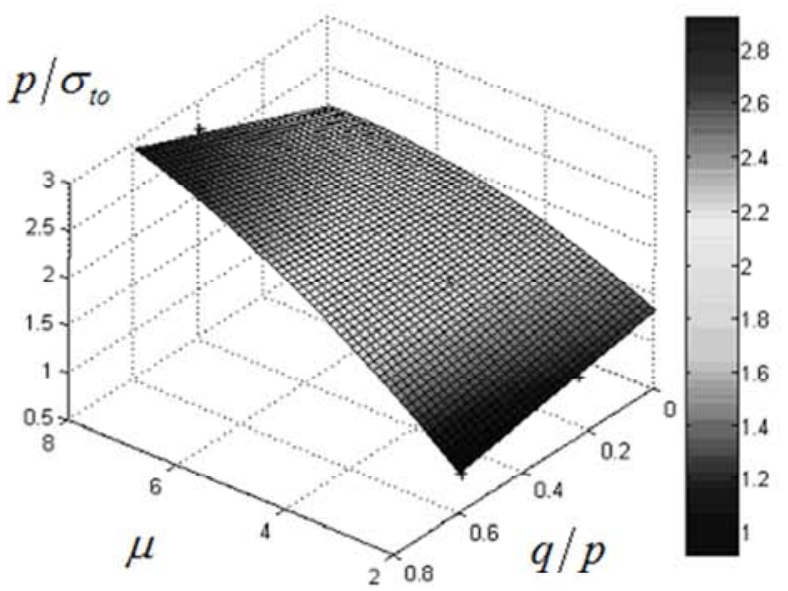

a shown (Table 1).

Table 1. The scheme and the results of the investigation of the HE process.

\begin{tabular}{llllll}
\hline \multirow{2}{*}{ Friction ratio, $\boldsymbol{\Psi}$} & \multirow{2}{*}{ Process value } & \multicolumn{2}{l}{ Draw $\boldsymbol{\mu}$} \\
\cline { 3 - 6 } & $\mathbf{2}$ & $\mathbf{4}$ & $\mathbf{6}$ & $\mathbf{8}$ \\
\hline \multirow{4}{*}{0,1} & $q, \mathrm{MPa}$ & 100 & 200 & 300 & 400 \\
& $P \times 10^{4}, \mathrm{~N}$ & 2,71 & 4,22 & 5,2 & 6,37 \\
& $\omega$ & 0,308 & 0,293 & 0,172 & 0,175 \\
0,2 & $q, \mathrm{MPa}$ & 200 & 100 & 400 & 300 \\
& $P \times 10^{4}, \mathrm{~N}$ & 2,14 & 4,32 & 5,45 & 6,61 \\
& $\omega$ & 0,32 & 0,31 & 0,205 & 0,179 \\
0,3 & $q, \mathrm{MPa}$ & 300 & 400 & 100 & 200 \\
& $P \times 10^{4}, \mathrm{~N}$ & 2,46 & 4,36 & 5,75 & 6,67 \\
0,4 & $\omega$ & 0,271 & 0,184 & 0,17 & 0,239 \\
& $q, \mathrm{MPa}$ & 400 & 300 & 200 & 100 \\
& $P \times 10^{4}, \mathrm{~N}$ & 2,68 & 4,53 & 5,7 & 6,82 \\
& $\omega$ & 0,326 & 0,164 & 0,12 & 0,176 \\
\hline
\end{tabular}

According to the results of the calculation experiment we chose the mathematical model for definition the damage factor (1)

$$
D_{f}=b_{1}+b_{2} \mu+b_{3} \frac{q}{p}+b_{4} \mu \frac{q}{p}+b_{5} \mu^{2}+b_{6}\left(\frac{q}{p}\right)^{2}
$$

where $D_{f}$ - damage factor (Cockcroft-Latham damage model); $\mu$-draw; $q / p$ - ratio of the lateral pressure to the stress of extrusion; $b_{1}, b_{2}, b_{3}, b_{4}, b_{5}, b_{6}$ - constant coefficients.

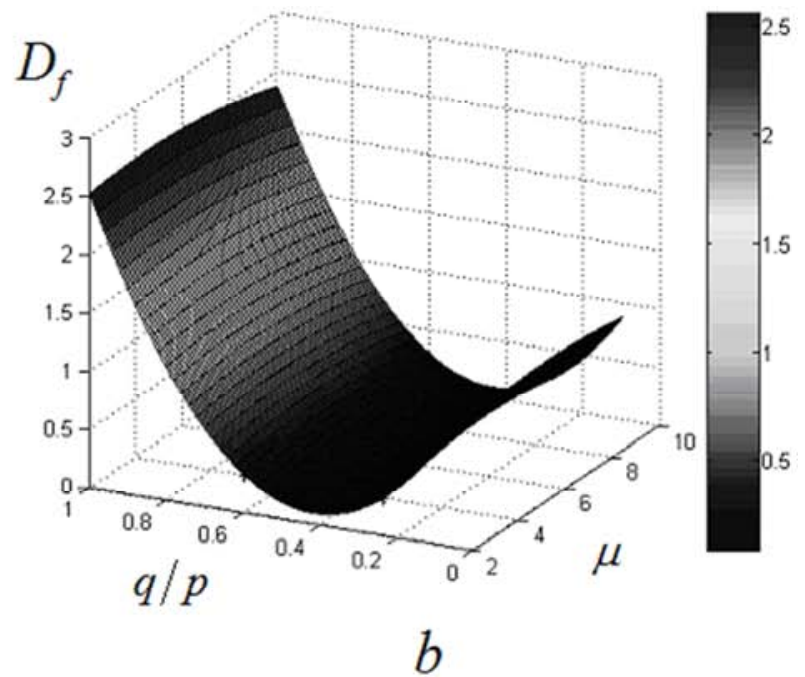

Figure 6. Specific extrusion stress (a) and damage factor $D_{f}$ (b) as functions of the draw $\mu$ and the ratio of the lateral pressure to the stress of extrusion $q / p$.

To determine the relationship (1) we carried out the regression analysis of the experiment results shown in Table 1 and Figure 6a. Statistical processing of the experimental data using the computer mathematics system MATLAB gave a possibility to get the following regression equation:

$$
D_{f}=1,1537+0,0872 \mu-5,789 \frac{q}{p}-0,0329 \mu \frac{q}{p}-0,0062 \mu^{2}+7,0712\left(\frac{q}{p}\right)^{2}
$$

The analysis of the simulation results allowed recognizing the optimal parameters of the HE process on the condition of minimizing the damage factor. With the draw value $\mu=2$ and the ratio of the lateral pressure to the stress of extrusion 
equal $q / p=0,42$ the Cockcroft-Latham damage factor equals $D_{f}=0.0917$. Since at production of rod pieces there is a limitation of the draw $\mu \geq 4$, the optimal process parameters of the hydromechanical extrusion on the condition of minimizing the damage factor are $q / p=0,42$. Thus, the value of the damage factor increases from $D_{f}=0.1639$ to $D_{f}=0.1863$ when the draw value changes from 4 to 6 . The further increase of the draw leads to reduction of the damage factor to the values $D_{f}=0.1789$ and $D_{f}=0.159$ for $\mu=7$ and $\mu=8$ respectively. The optimal value of the ratio of the lateral pressure to the extrusion stress remains constant and equal $q / p=0,42$.

Based on the results obtained at simulation of the HE process of the aluminum alloy we chose the mathematical model (3) to describe the value of the specific extrusion stress.

$$
\frac{p}{\sigma_{t o}}=a_{1}+a_{2} \mu+a_{3} \frac{q}{p}+a_{4} \mu \frac{q}{p}+a_{5} \mu^{2}
$$

where $p$ - extrusion stress; $\sigma_{t o}$ - initial value of yield stress; $\mu$-draw; $q$ - pressure to lateral side of the workpiece (lateral pressure); $a_{1}, a_{2}, a_{3}, a_{4}, a_{5}$ - constant coefficients.

Using the computer mathematics system MATLAB we formed the dependence of the specific extrusion stress $p / \sigma_{t o}$ on the draw $\mu$ and the ratio of the lateral pressure to the extrusion stress $q / p$ (Fig. 6b). Statistical processing of the experimental data using the computer mathematics system MATLAB allowed receiving the following regression equation:

$$
\frac{p}{\sigma_{t o}}=0,6899+0,3594 \mu+1,3655 \frac{q}{p}+0,3526 \mu \frac{q}{p}-0,0238 \mu^{2}
$$

According to the simulation results it can be concluded that with draw increase the specific extrusion stress increases from 0.9 to 2.86 . It is recommended to use a draw specified from the permissible value of the pressure on the punch. Thus, when $p_{p e r} / \sigma_{t o}=2.5$ and $q / p=0,42$ the maximum draw equals $\mu=7$.

The proposed method can be used to study the process of the hydromechanical extrusion of hard-to-deform metal materials.

\section{Conclusion}

The methodic of the computer-aided engineering analysis and the design of a new technological process such as the HE process was worked out. In the developed software system as a result of the integration of several specialized packages the system of computer-aided design of technology and equipment for implementation of the high-performance HE process producing the simulation of the process, the calculation of the basic power parameters, the test of strength and the development of assembly drawings and parts tooling was created. The analysis of the results of HE process simulation is presented in a visual form and shows that use of active friction forces reduces the extrusion force.

When developing the software the problem of introducing a new technological process into the existing software environment was solved. The developed software system can be widely used in development of new technologies and optimization of existing technologies as well as a study aid for construction of complex integrated software systems.

\section{References}

[1] Zalazynskii, A. G. Plastic Deforming of Structurally Inhomogeneous Materials // Yekaterinburg: UrO RAN, 2000, $492 \mathrm{p}$.

[2] Danilin, A. V. Investigation of the Stress-Strain State and the Particularities of the Metal Flow during Direct Pressing and SPAT Pressing of Hard-to-Deform Alloys// Russian Journal of Ferrous Metals, 2004, No. 5, p.45.

[3] Kolmogorov, G. L., Mikhailov, V. G., Barcov, Yu. A., Karlinski, V. A. Hydropressing of Hard-to-Deform Refractory Metals and Alloys // Metallurgy, Moscow, 1991, 142 p.

[4] Pachla, W., Kulczyk, M., Sus-Ryszkowska, M., Mazur, A., Kurzydlowski, K. J. J. Mater. Process. Technol., 205 (2008), p. 173.

[5] Zherebtsov, S., Mazur, A., Salishchev. G., Lojkowski, W. Mater. Sci. Eng. A, 485 (2008), p. 39.

[6] Zherebtsov, S., Salishchev, G., Łojkowski, W. Strengthening of a Ti-6Al-4V titanium alloy by means of hydrostatic extrusion and other methods, Materials Science and Engineering: A, Volume 515, Issues 1-2, 25 July 2009, Pages 43-48.

[7] Bridgeman, P. W. Studies in large plastic flow and fracture, MC Graw-Hill, New-York, 1952.

[8] Beresnev, B. I., Gaivoronskii, A. T., Zamaraev, V. K., and others. Hydraulic Forging // Yekaterinburg: Inst. Prikl. Mekh. UrO RAN, 1998-241 p.

[9] Kolpashnikov, A. I., Vyalov, V. A. Hydraulic Forging of Metals // Moscow: Metallurgiya, 1973.

[10] Zalazinskii, A. G., Byvaltsev, S. V., Zalazinskaya, E. A., Agapitova O. U. Modelling of process of hydromechanical extrusion // Electronic Journal "Investigated in Russia", 2010, no. 13 , p. $542-551$.

[11] Agapitova, O. U., Byvaltsev, S. V., Zalazinskii, A. G. Improvement of hydromechanical extrusion of non-ferrous metals // Russion Journal of Non-ferrous Metals, 2011, no. 52 (4), p. 382-387.

[12] Agapitova, O. U., Byvaltsev, S. V., Zalazinskii, A. G. Features of processes of direct and hydromechanical extrusion billets // Forging and Stamping Production. Material Working by Pressure, 2013, no. 10, p. 36-40.

[13] Agapitova, O. U., Byvaltsev, S. V., Zalazinskii, A. G. Determination of rheological properties of plastoparaffin for simulation of metal forming processes // Handbook. An Engineering journal with appendix, 2012, no. 12 (189), p. 3-5. 
[14] Byvaltsev, S. V., Zalazinskii, A. G., Polakov, A. P. Intelligent control system is the pressing process // Handbook. An Engineering journal with appendix, 2008, no. 9, p. 43-48.

[15] Byvaltsev, S. V., Zalazinskii, A. G., Polakov A. P. Experimentaly-analytical method for the determination of damage in composite drawing process // Universities Proceedings. Non-ferrous metallurgy, 2008, no. 4, p. 26-32.

[16] Byvaltsev, S. V., Zalazinskii, A. G. The program complex mathematical metal forming process simulation // State Fund of algorithms and programs, no. 50200702222.

[17] Agapitova, O. U., Byvaltsev, S. V., Zalazinskii, A. G. Computer-aided design tools based on modeling technology of extrusion of metals // Software \& Systems, 2012, no. 3, p. 228-233.
[18] Tinkir, M., Dilmec, M., Turkoz, M., Halkaci, H. S. Investigation of the effect of hydromechanical deep drawing process parameters on formability of AA5754 sheets metals by using neuro-fuzzy forecasting approach // Journal of Intelligent \& Fuzzy Systems, 2015, no. 28 (2), p. 647-659.

[19] Zalazinskii, A. G., Byvaltsev, S. V. Program Complex for Realization of the Experimental and Analytical Method of Modeling the Processes of Metal Workpieces Deformation // Vestn. Komp. Inf. Tekhnol., 2006, no. 11, p. 46-51.

[20] 12Kolmogorov, V. L. Mechanics of Pressure Treatment of Metals // Yekaterinburg: UGTU-UPI, 2001, 836 p. 